\title{
Latvian health care competitiveness in relation to its infrastructure and available resources
}

\author{
A. Kokarevica, A. Villerusa, D. Behmane, U. Berkis, and V. Cauce \\ Rīga Stradiņš University, Riga, Latvia
}

\begin{abstract}
Resources are one of the essential indicators for the functioning of the health care system. Better health care provision is an essential prerequisite for the export of services. Traditionally a competitive health care system is linked to a number of factors (price, quality, reliability, products and services) largely determined by the new technologies, innovations and implementation the new methods. The authors of this article analyzed and collected data from the European Commission Eurostat and OECD data. Current situation in health care in Latvia is characterized by populations' restricted access to health care services, high out-of-pocket payments and poor health outcomes of the population. More than $10 \%$ of Latvian population can't afford medical care. The ratio of public funding for healthcare in Latvia is among the lowest in EU countries. Latvia spends 5.3\% (USD PPP 1217) of GDP on health, lower than the OCED country average of $8.9 \%$ (USD PPP 3453 ). Latvia is facing a dramatic gap between the availability of hospital beds and long term care beds and the lowest prevalence of general medical practitioners among all Baltic States 321.6 per 100 000. These mentioned factors may hinder the development of health care in Latvia and reduce the ability to participate in international health service market.
\end{abstract}

\section{Introduction}

Good health benefits in all sectors of economy and the whole of society are making it a valuable resource. Good health is essential for economic and social development and a vital concern to the lives of every single person, all families and communities. As stated in the World Health organizations (WHO Constitution): "The enjoyment of the highest attainable standard of health is one of the fundamental rights of every human being". To achieve this goal it is necessary to target the health inequities and inequalities in the country. The Health 2020 strategy stresses that investing in health makes sense, especially by growing the GDP for health. Of the increase in health spending, 92\% correlates with positive growth in gross domestic product (GDP). In recent years European health systems are being required to improve their performance and respond to new challenges.

Prioritizing investment in public health institutional arrangements and capacity building, and efforts to strengthen health protection, health promotion and disease prevention can have important cost-effective benefits. Reconfiguring services and responsibilities, redesigning incentives and payment structures, and being attentive to return on investment can result in improved value for money [1]. The WHO in their Framework 
for Action towards coordinated/integrated health services states, that to improve the health of the Europeans and to achieve the Health 2020 goals there must be shifting to people centered health systems and services. From the perspective of the system, patient-centred services delivery must strive to provide comprehensive, coordinated, quality, and equitable care and it is in the pursuit of these performance gains that the system must act. Importantly, the provision of services takes direction from the system-at-large and is derived from the conditions it creates. Thus, the success of transformations towards patientcentred health services rests on an understanding of both the root causes (determinants) of poor performance of the function itself and the contributions of the health system underpinning the provision of health services [2].

In most countries, universal health coverage provides financial protection against the cost of illness and promotes access to care for the whole population. Health spending now accounts for about 9\% of GDP on average in European countries, and exceeds $10 \%$ in several countries. Higher health spending is not a problem if the benefits exceed the costs, but there is sample evidence of inequities and inefficiencies in health systems which need to be addressed. There is also a need to achieve a proper balance between spending on disease prevention and treatment [3]. Despite these improvements, important questions about how successful countries are in achieving good results on different dimensions of health system performance remain.

Contemporary health systems are faced with an important paradox. On the one hand, consistent increases in health care investments over past decades and major developments in biomedical research have resulted in an extraordinary expansion of knowledge, technologies, techniques, skills and resources that make it possible to tackle many major health problems more effectively than ever before. On the other hand, many recent attempts to reform the health care sector have had only limited success in the quest to develop a more effective, efficient, safe and equitable delivery system that achieves the fundamental goal of improving population health [4].

One of the main challenges and risks that are influenced by insufficient health infrastructure is a gap between countries in health status and health inequalities. Latvian health system has one of the lowest levels of funding in the EU for medical expenses. As regards most health system performance criteria, such as health status, financial risk protection, and patient satisfaction, Latvia still lags behind not only western EU countries, but also other countries that joined the EU in 2004. The Latvian health care system is based on general tax-financed statutory health care provision, with a purchaser-provider split and a mix of public and private providers. The Ministry of Health is responsible for national health policy and the overall organization and functioning of the health system. The independent National Health Service (NHS) institution implements state health policies and ensures the availability of health care services throughout the country. Different ownership structures characterize health care provision in Latvia. Smaller hospitals and some bigger regional hospitals are usually owned by some of the 119 municipalities, whilst larger tertiary hospitals (university hospitals) and single specialty (monoprofile) hospitals (e.g. psychiatric hospitals) are owned by the state. Most primary care physicians have the legal status of an independent professional, and almost all dental practices and pharmacies are private [7].

In recent years, the economic crisis has constrained the financial resources available and thus increased Member States' difficulties in ensuring their health systems' sustainability. In turn, this could jeopardize Member States' ability to provide universal access to good quality healthcare. Ensuring universal access to cost-effective healthcare, including health promotion and prevention, in a financially sustainable manner is essential both for social cohesion, and for long-term economic growth, as a healthier population will improve labour market participation and labour productivity. 
There are three widely accepted goals in the organization of health care in Europe: care should be of high quality, it should be comprehensive and it should be made available without financial barriers to access. These are not the only important goals, but they define a set of core policy purposes. Public policy works well when it combines the three core purposes in acceptable ways; however, achieving such combination becomes ever more challenging as the tensions between them increase under pressure of background trends such as an ageing population, technological innovation and a global rise in healthcare costs [8].

The aim of this report is to analyze the Latvian health care performance in relation to its infrastructure and available resources, in comparison with Baltic and some Scandinavian countries. The main objective is to discover the main differences and issues in order to improve health care delivery for local population and facilitate competitiveness in region. This will be part of a bigger picture involving the market structure for healthcare; Latvia has pretty liberal legislation for healthcare professions, the powers of the certified medical professional are very substantial. This indicates that the system can nurture significant competitive order in the Euckenian sense, and develop market pressure, optimizing the costs. To initiate rational studies of market power in healthcare, uncovering of the market mechanism is challenging in case where on demand side very strong rationing persists. In this case it is not easy to estimate the equivalent market power to unrestricted competition, as will be the case for the external markets. An intermediary stage will be the system based on procurements, which is slowly developing in Latvia.

\section{Materials and methods}

In this article a secondary data from EU level data sources, reports and literature analysis is used. The authors of this report analyzed and collected data/information using the following keywords: health care performance, resources, health infrastructure, health inequalities, health care expenses, medical personnel and technology. The data used for the analysis in this report is extracted for the European Commission Eurostat data base and Organization for Economic Co-operation and Development (OECD) data.

\section{Results and discussion}

The public sector plays a major role in the financing of health services: in two thirds of EU Member States, more than $70 \%$ of health expenditure is funded by the public sector. In 2014 in the EU-28, total expenditure of general governments on "health" amounted to $7.2 \%$ of GDP. "Hospital services" accounted for 3.6\% of GDP, "outpatient services" for $2.2 \%$ of GDP and "medical products, appliances and equipment" for 1.0\% of GDP [9]. The ratio of public funding for healthcare in Latvia is among the lowest in EU countries. Latvia spends $5.3 \%$ (USD PPP 1217) of GDP on health, lower than the OCED country average of $8.9 \%$ (USD PPP 3453). Accessibility (including affordability) of healthcare services is a topical policy issue in Latvia. The most important causes of the limited accessibility of healthcare services are: lack of funding, lack of human resources, high out-of-pocket payments, regional disparities in service provision and low solvency of patients. The share of health expenditure as a percentage of total general government expenditure declined from $10.6 \%$ in 2008 to $9.2 \%$ in 2010 and the Ministry of Health budget dropped by $12.6 \%$ in 2009 and by $1.5 \%$ in 2010 , public health expenditure constituting around $3 \%$ from GDP. The growth of recent years is insufficient. In 2017, funding for the health sector only by approximately 30 million will exceed the pre-crisis level in 2008. Fiscal adjustments led to a broad spectrum of reforms affecting hospital and secondary ambulatory services as well as public 
health programs. As shown below (see Fig. 1), than Latvia has the lowest GDP expenditure on health among all Baltic states and one of the smallest among other EU-28 states. The biggest spending from the GDP goes to medical and outpatient services (see Fig. 1).

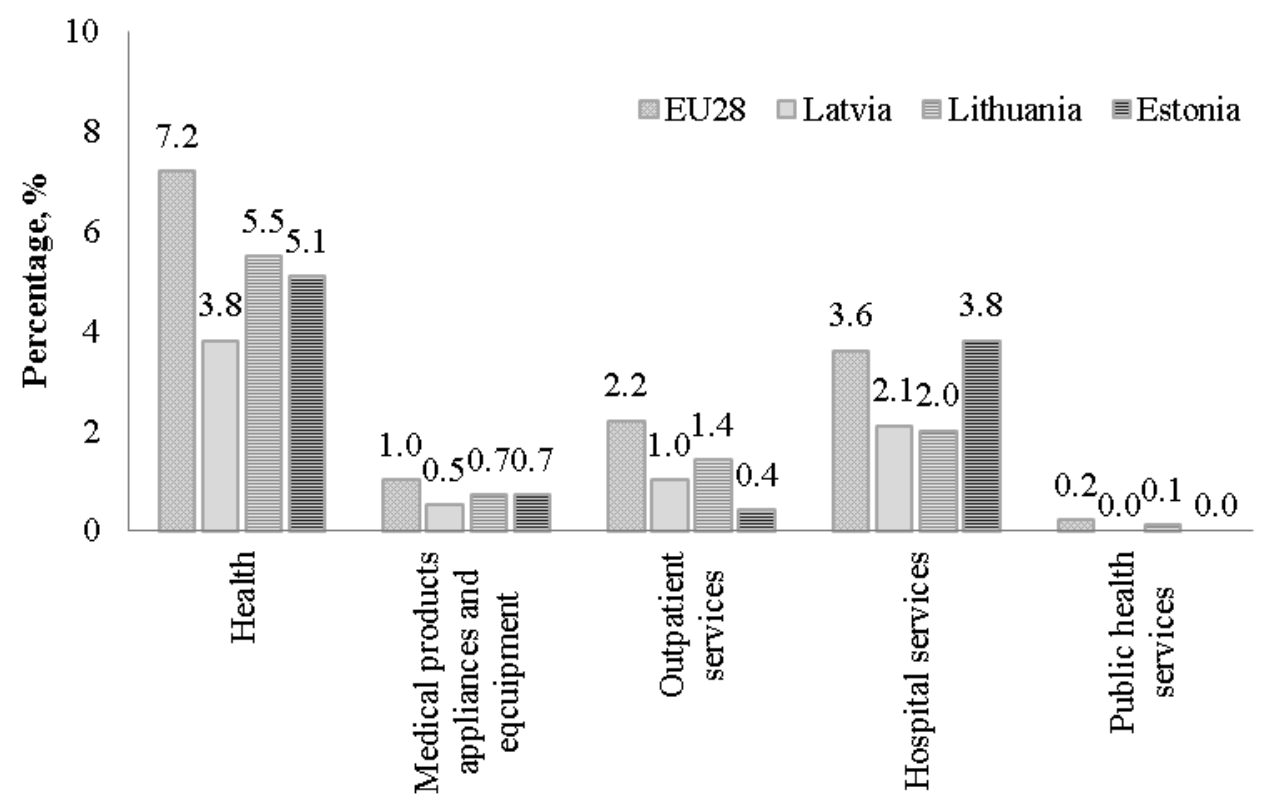

Fig. 1. GDP per country and service (\%) (Data of 2014). Source: Eurostat, 2014.

Growth in health spending in Latvia has been modest compared to overall economic growth. Real GDP growth in Latvia averaged about $9 \%$ in $2002-07$, and then concentrated sharply by $3.6 \%, 14.3 \%$ and $3.6 \%$ between 2008 and 2010 , finally picking up again at around 3\% annual growth until recent slowdown. Prior the global financial crisis, between 2005-2009 health spending in Latvia increased by 3\% per year, slower the OCED average of 3.4\% annual growth. Between 2009 and 2013, Latvian health spending growth was no different to the OCED average at $0.6 \%$ per year [6]. As shown in the Fig. 2. Latvia has the lowest per capita spending on health between the Baltic and selected Scandinavian countries.

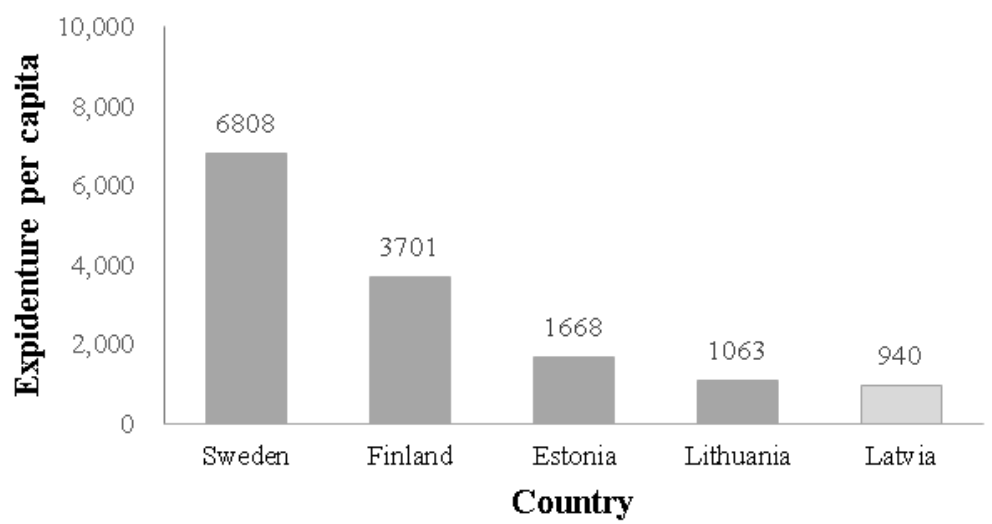

Fig. 2. Health expenditure per capita per country (PPP 2011 \$). Source: OCED, 2014. 
Latvia is facing a dramatic gap between the availability of hospital beds and long term care beds. Per 100000 inhabitants there are only 60.6 long term beds available in the country (see Fig. 3). Facing the ageing of the population and the increasing demand, Latvia is facing serious difficulties to meet this demand, and it is predicted that in the future there will be an even greater risk to the population not to receive this service.

In 2014 , more than three quarters $(76.0 \%)$ of all beds in EU-28 hospitals were for curative care, $14.0 \%$ for rehabilitative care and the remaining $10.0 \%$ for long-term care and other purposes.

\section{$\square$ Available hospital beds $\square$ Currative care $\square$ Long term care beds}

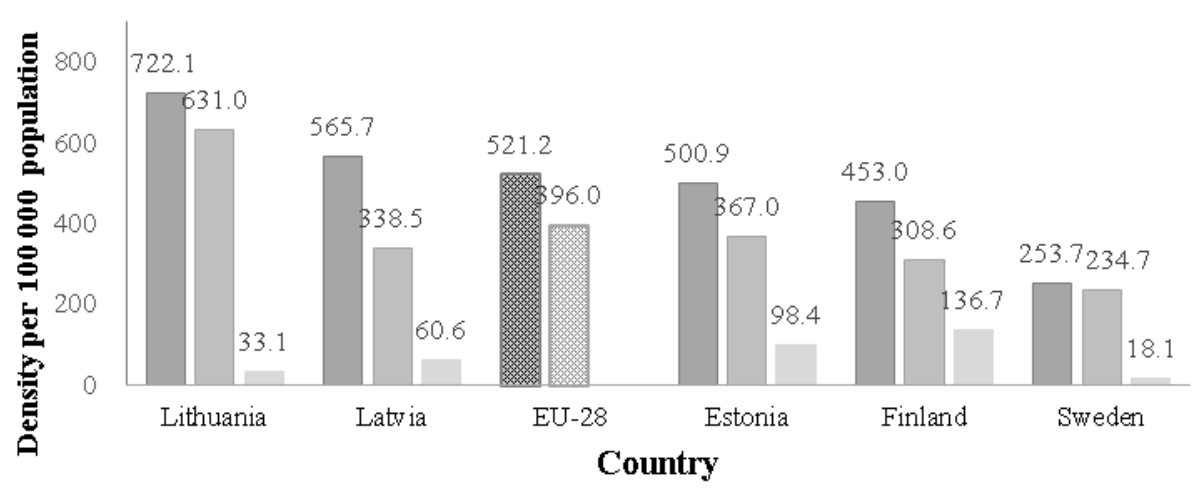

Fig. 3. Hospital beds by type of care in 2014 (per 100000 inhabitants). Source: Eurostat, 2014.

The importance of human resources for the sustainable development of health sector has been neglected during the reform path since the start of economic crisis in Latvia. The "Basic Statement on Development of Human Resources for Health Care" was adopted by the Cabinet of Ministers in 2006. The policy envisaged the adoption of staffing requirements for physicians and nurses per bed and patient by specialty in hospitals. In addition, the document suggested a plan for the increase in health care personnel remuneration levels to promote recruitment of new doctors and retain existing staff. However, as a result of financial constraints in the context of the economic crisis, salaries of health professionals have, in general, been reduced rather than increased in recent years. The adopted Workforce strategy (adopted in 2006) was suspended in 2010 and the strategic vision regarding the supply, structure and remuneration of human resources has been lost.

In 2013 in Latvia there were 6172 practicing physicians, or 3.19 per 1000 inhabitants, which is on the EU average level. Of these 1313 or $21.3 \%$ were family doctors. In overall, the total number of medical doctors during 10 years period has decreased by $4 \%$, but number of practicing medical doctors by $3 \%$. Shortages of some professional groups are anticipated. There are 3.1 practicing doctors per 1000 population, close to the OCED average of 3.2, but many doctors are retiring in coming decades. The average age of Latvian GPs is 54. More than two-thirds of practicing GPs are aged 50 and over, and more than a quarter of them are aged 60 and over [6].

Latvia has two higher medical education faculties, which is a relatively large number for a country of this size. The number of medical practitioners who have left the healthcare sector is substantial. This silent reserve has been tried to activate e.g. via European Social fund activities for nurses. Latvia possesses purely non-governmental system of medical certification, and this is an important aspect in the forecasts. Particular evidence exists about medical practitioners leaving the sector in case they cannot secure anymore public quotas for rationed services purchases, which is of high significance for sparsely populated 
rural regions where out-of-pocket purchases of services is rare. Furthermore, competition for residency places is very high among university graduates

In comparison in the EU - 28 the "health and social work" sector is the sector which saw the largest rise in employment in recent years (and notably between the second quarter of 2008 and the second quarter of 2015) with over 2.6 million new jobs. With regard to absolute figures across the EU, the "human health and social sector" accounted for 23400500 employees in the second quarter of 2015. The majority of them - 13293700 employees - were employed in the "human health" subsector. Workers in the health and social work sector have an education level far above the average of all sectors [5]. The three most common types of physicians across the EU Member States are generalist medical practitioners, the medical group of specialists and the surgical group of specialists [9]. Latvia has the lowest prevalence of general medical practitioners (physicians) among all Baltic countries 321.6 per 100000 (see Fig. 4). The data could be explained and linked to the low wage rates among the medicines in Latvia - in year 2013 only $13.74 \%$ in the health sector employed earned a wage more than 1000 EUR. Comparison of the remuneration of health professionals between countries substantiates that the state policy in Latvia has been very shortsighted and there is an enormous gap between the publicly regulated doctor salaries in Latvia (annual salary 13936 EUR) and the EU countries [6].

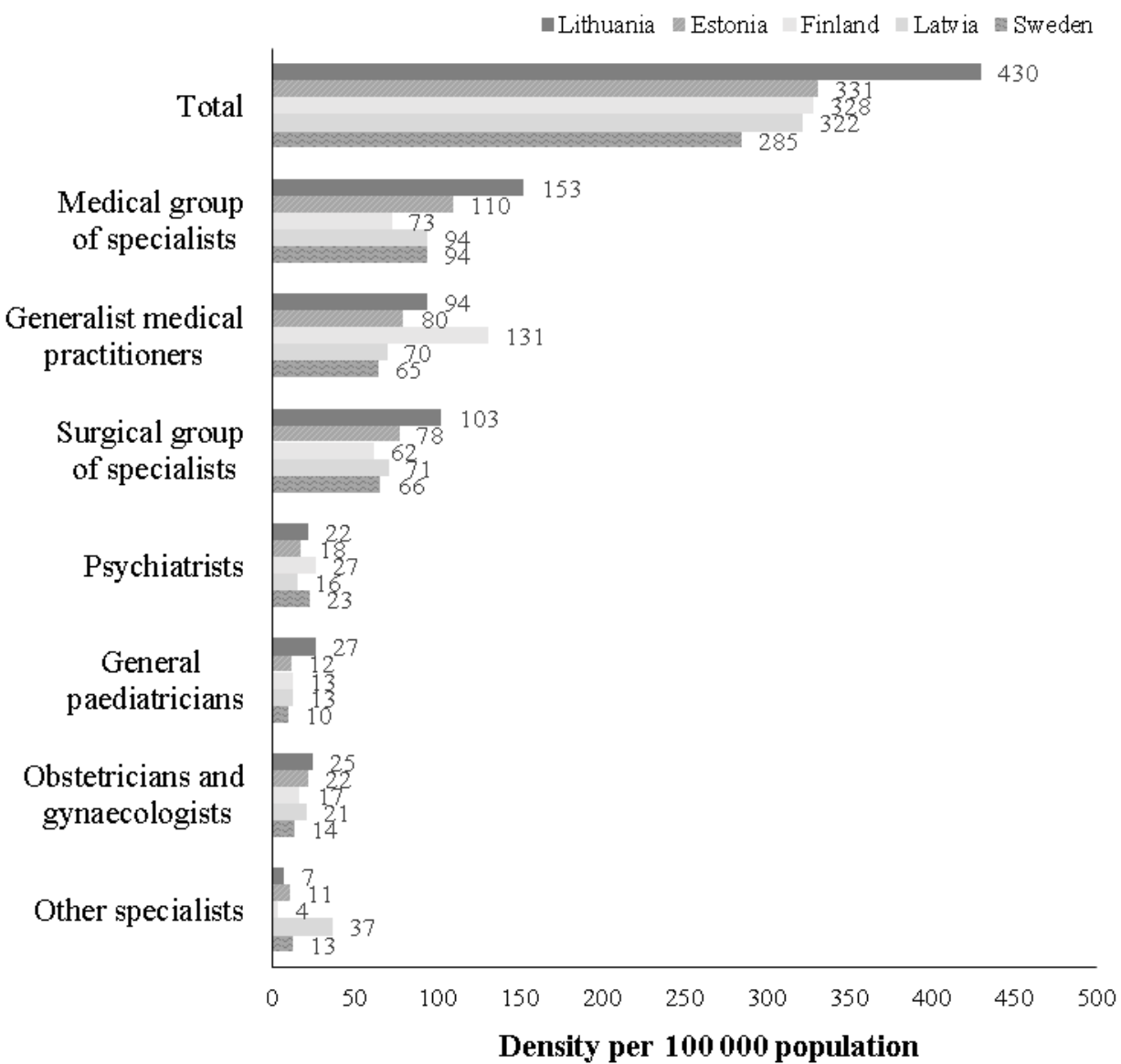

Fig. 4. Physicians by specialty per 100000 inhabitants (2014.data). Source: Eurostat, 2014. 
Recent analysis shows that the overall situation regarding health personnel in Latvia is an important bottleneck for system quality and efficiency. The number of medical graduates is 14 per 100000 of population, which is slightly above the EU average and is not a hurdle for the supply of labour in the sector. Nevertheless that educational system provides good basis for professional medical education, it does not correlate with the number of practicing doctors evidently highlighting the problem of retention of medical graduates in the country (see Fig. 5).

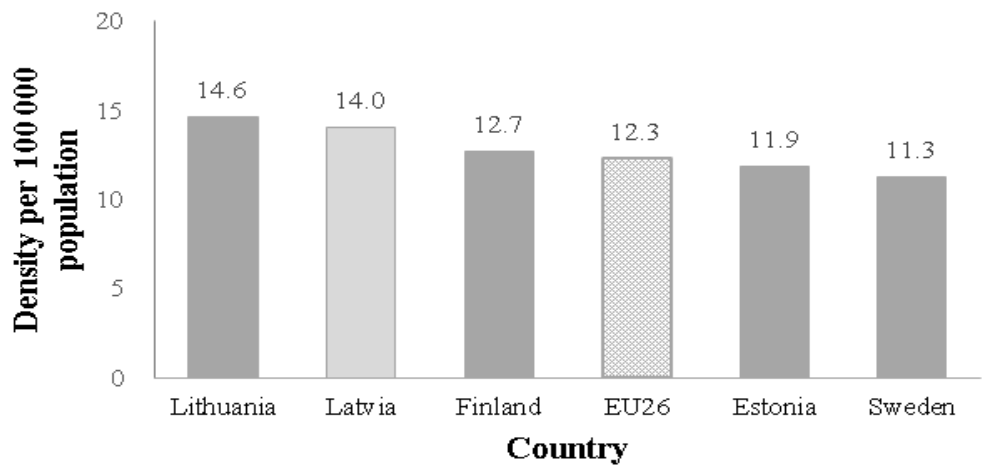

Fig. 5. Medical graduates per 100000 inhabitants, 2013. Source: OECD (2016), Medical graduates.

The number of practicing nurses is even a greater concern. The age of nurses and other supporting professionals is also increasing, making it challenging to secure their future supply [6]. The supply of middle level workforce in comparison to doctors is very low. The number of nurses is on the bottom level between EU/EEA countries: 4.8 nurses per 1000 inhabitants in 2013, which is around 2 times less than the average EU countries (see Fig. 6).

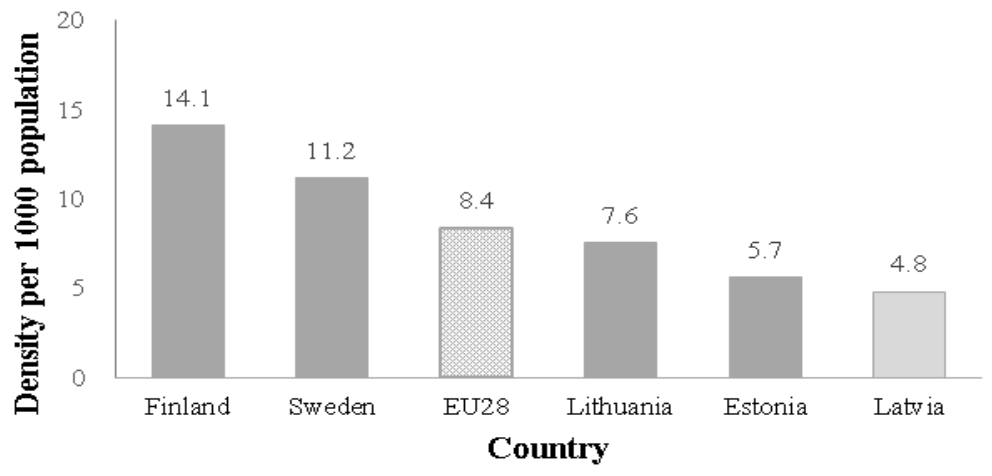

Fig. 6. Practicing nurses per 1000 population, EU countries, 2013. Source: OECD (2016), Practicing nurses.

The ratio of nurses to physicians in Year 2015 in Latvia was 1.5 in comparison with the EU 28 average -2.5 , in Finland -4.7 , Sweden -2.7 . Very close, but slightly less than the other Baltic countries: Estonia -1.7 and Lithuania -1.8 .

Much better situation in Latvia is with the high-tech availability ratio per 100000 inhabitants, which demonstrates the possibilities and capacity of a countries health care force. The availability of equipment for diagnosis has increased rapidly over recent decades in Latvia, which could be a positive prerequisite for service volumes increase, including foreign patient's attraction. Latvia has a high availability of CT scanners and MRI units 
(3.6 and 1.3 per 100000 inhabitants) (2014.data), what demonstrates an opportunity to compete not only on local (Baltic countries) level, but also internationally.

Table 1. Availability of medical technology - imaging equipment - (2014) per 100000 inhabitants. Source: Eurostat, 2014.

\begin{tabular}{|l|c|c|c|c|c|c|}
\hline Country & $\begin{array}{c}\text { CT } \\
\text { scanners }\end{array}$ & $\begin{array}{c}\text { MRI } \\
\text { units }\end{array}$ & $\begin{array}{c}\text { Gamma } \\
\text { cameras }\end{array}$ & $\begin{array}{c}\text { Angiograp } \\
\text { hy units }\end{array}$ & $\begin{array}{c}\text { Mammo } \\
\text { graphy }\end{array}$ & $\begin{array}{c}\text { PET } \\
\text { scanners }\end{array}$ \\
\hline Latvia & 3.6 & 1.3 & 0.3 & 0.6 & 2.3 & 0.1 \\
\hline $\begin{array}{l}\text { Lithuani } \\
\text { a }\end{array}$ & 2.2 & 1.1 & 0.3 & 0.8 & 1.4 & 0.1 \\
\hline Estonia & 2.0 & 1.1 & 0.2 & 0.9 & 1.0 & 0.2 \\
\hline Finland & 8.1 & 2.3 & 0.8 & 2.0 & 3.1 & 0.2 \\
\hline EU 28 & 2.1 & 1.5 & $\ldots$ & $\ldots$ & $\ldots$ & $\ldots$ \\
\hline
\end{tabular}

In most of all cases Latvia is the leading country in Baltic States in the availability of new technologies per 100000 inhabitants. The frequently used and available technology is CT scanners and MRI units (see Table 1).

An indicator frequently used to show barriers in access to health care is patient selfreported unmet needs based on surveys. Reasons given for not receiving care include: excessive treatment costs, long waiting times, or having to travel too far to receive care [5]. Current situation in health care in Latvia is characterized by populations' restricted access to health care services, high out-of-pocket payments and poor health outcomes of the population. Overall in the EU-28, the most common reason for not having a medical examination or treatment was that it was too expensive; this reason alone accounted for one third of all the people who reported an unmet need for medical care, equivalent to $2.4 \%$ of the population. As shown in Table 2, than Latvia has the highest unmet need prevalence between all Baltic States and between all EU-28 countries (in 2014, 12.5\% as opposed to $3.7 \%$ for the EU-28 average; EUROSTAT, 2014) (Year 2014.data) [9]. The cost of healthcare service is the main factor restricting the accessibility of healthcare services $[10,11]$. The high rate of people who can't meet her need for health treatments are showing that Latvia is lacking both - finances and infrastructure for the health system. The most common reason for unmet need are the expenses for health care $(12.5 \%)$ people need to cover from their own budget which in most cases (most of the people who reported that they can't afford the health care they need where over 70 years of age) is not possible. More than $10 \%(10.5 \%)$ of Latvian population can't afford medical care (see Table 2).

Table 2. Share of persons aged 16 and over reporting unmet needs for medical care, by detailed reason (2014 or latest available) (\%). Source: Eurostat, 2014.

\begin{tabular}{|l|c|c|c|c|c|}
\hline \multirow{2}{*}{ Countries } & \multirow{2}{*}{ All reasons } & \multirow{2}{*}{\begin{tabular}{c} 
Health \\
related \\
\cline { 4 - 6 }
\end{tabular}} & & \multicolumn{3}{|c|}{ Of which } \\
\cline { 4 - 6 } & & reasons & To & To far to & Waiting \\
expensive & travel & list \\
\hline EU 28 & 6.7 & 3.6 & 2.4 & 0.1 & 0.1 \\
\hline Latvia & 19.2 & 12.5 & 10.5 & 0.4 & 1.6 \\
\hline Lithuania & 5.4 & 3.7 & 0.7 & 0.3 & 2.7 \\
\hline Estonia & 13.1 & 11.3 & 0.5 & 0.7 & 10.1 \\
\hline Finland & 4.7 & 3.3 & 0.1 & 0.0 & 3.1 \\
\hline Sweden & 9.2 & 1.5 & 0.5 & 0.1 & 1.0 \\
\hline
\end{tabular}


The self-reported unmet medical needs should also be seen in the context of objective measures of the use and expenditure on healthcare, such as the level of public, private and "out of pocket spending" on health care, which also provide information related to the financial protection of the population against the risks of ill-health, as well as the actual use of health services. As shown in Fig. 7, than Latvia has the highest rate of reported privatehousehold out of pocket expenditures in all Baltic States and 17\% than in EU-28 member states.

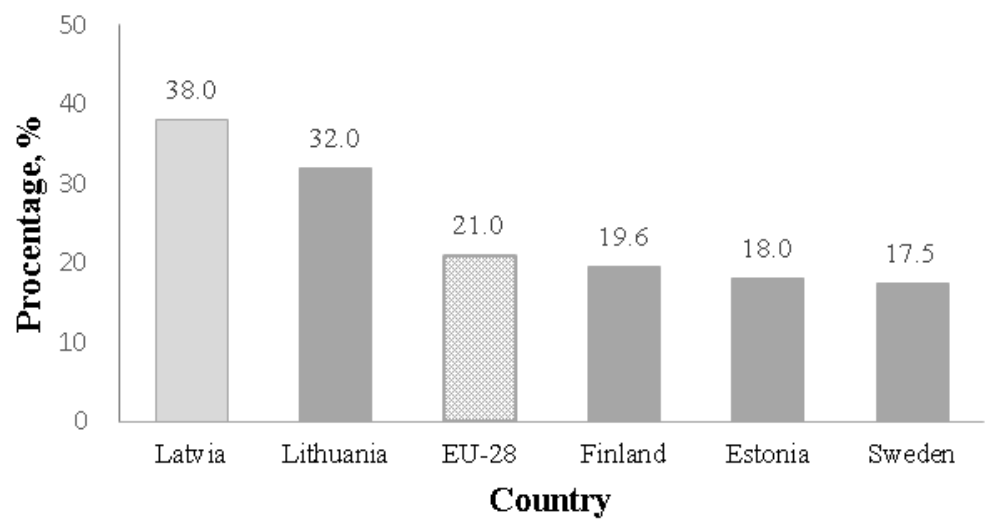

Fig. 7. Private household out-of-pocket expenditure as $\%$ of total current health expenditure, 2013 or latest available. Source: Eurostat, 2014.

To understand the competitive health care options and potentially necessary investments in health care and health care workforce, as well as to complete understand the consequences of under-investment in health care and prevention system of a country, it is need to be clear that in the last decade health expenditure of a state is of interest from two perspectives. Firstly, increasing costs for labor and constant inefficiencies in the organization of healthcare production push overall expenditures of healthcare. Secondly, the way production of healthcare is organized affects the productivity effect of investments in new technology and innovation. Preferably, a higher capital share in the production will increase productivity, partly by substituting labor and old technology, partly by making production more efficient. But this is not necessarily the case with investments in any sector, and it seems safe to say that healthcare have shown particularly small effects on productivity by investments. Healthcare service is largely a non-tradable sector. It is integrated with world markets in some aspects on the input side, but the service output is in most countries detached from world markets. Yet increasing elements of health-care services have grown more tradable. However technological progress, like teleradiology, and increased mobility of labour and capital have fostered greater interests for cross-border healthcare services, although still only at the margin [9].

\section{Conclusions}

- Assessing the available data and information, one can see that Latvia has great opportunities, capability and potential for further improvement among European Union member states in the field of health care. The high availability of high-tech and low personnel costs, favorable geographical location may provide the potential for attracting medical tourists from the West and the East as well. 
- Nevertheless the development of the Latvian health care system performance and its competitiveness is negatively affected by the relatively low level of public investment from GDP in the sector. To develop the health care enough fit the needs of the country's population the government needs to invest at least $6 \%$ of GDP. High levels of cost sharing for almost all service users create some financial barriers to access and large proportion of unmet needs of patients.

- Improvement in workforce structure and planning is essential for reaching Health 2020 goals - as improvement of population's health, reducing inequalities and to ensure patient centred health system. These mentioned factors may hinder the development of health care in Latvia and reduce the ability to compete with other countries.

- Latvia demonstrates a complex interaction between demand and supply side on the healthcare market in case of strong rationing of public demand combined with demand insufficiency of privately funded services, exaggerated by regional disparities and still severe consequences from 2008 crisis.

The research has been supported by National Research Programme "EKOSOC-LV" project 5.2.1 "Research on Latvian enterprises competitiveness in external markets and its improvement", subproject "Healthcare industry external competitiveness".

\section{References}

1. World Health organization, Health 2020 - European Policy framework and strategy for the 21st Century, World Health organization, 5-25 (2013)

2. World Health organization, Health Services Delivery Programme Division of Health Systems and Public Health, World Health organization, 10-15 (2014)

3. C. Etienne, A. Asoma-Baah et al., Health systems financing, the path to universal coverage, The World Health report, World Health organization, 8 (2010)

4. R. Bernd, C.-A. Dubois, M. Mckee, the Health care Workforce in Europe, Learning form experience, European Observatory on Health Systems and Policies, 15-20 (2006)

5. European Commission, Questions and answers on Solidarity in health: Reducing health inequities in EU, http://europa.eu/rapid/pressrelease_MEMO-09-467_en.htm?locale=en (2009)

6. Organization for Economic Co-operation and Development, OCED Reviews of health systems: Latvia, OCED Publishers, 14-30 (2016)

7. U. Mitenbergs, M. Taube, J. Misins, E. Mikitis, A. Martinsons, A. Rurane, W. Quentin, Health Systems in Transition, Latvia - Health system review, European Observatory, 14, No. 8, 22-40 (2012)

8. M. Marmot, R. Belt, P. Goldblatt, et al., The Future of Healthcare in Europe - a social determinants perspective, The Future of Healthcare in Europe, London's Global University, 7-15 (2012)

9. F. Erixon, M. nav der Marel, What is driving the rise in Health care expenditures? An Inquiry into the Nature and Causes of the Cost Disease, Ecipe working paper 5, 2-5 (2011)

10. European Commission, Health and health systems http://europa.eu/epc/pdf/joint_healthcare_report_en.pdf, 1-10 (2016)

11. European Commission, Changing the funding of the Latvian compulsory healthcare system: For better or for worse? ESPN Flash Report 2016/24, 1-2 (2016) 